January 2009

\title{
Efficacy and safety of intermittent preventive treatment with sulfadoxine-pyrimethamine for malaria in African infants: a pooled analysis of six randomised, placebo-controlled trials
}

\author{
J.J. Aponte \\ University of Barcelona \\ D. Schellenberg \\ London School of Hygiene and Tropical Medicine
}

\section{A. Egan \\ University of Barcelona}

\section{A. Breckenridge}

Medicines and Healthcare Products Regulatory Agency, London

\section{Carneiro}

London School of Hygiene and Tropical Medicine

See next page for additional authors

Follow this and additional works at: http://ecommons.aku.edu/eastafrica_fhs_mc_pathol

Part of the Pathology Commons

\section{Recommended Citation}

Aponte, J., Schellenberg, D., Egan, A., Breckenridge, A., Carneiro, I., Critchley, J., Danquah, I., Dodoo, A., Kobbe, R., Lell, B., May, J., Premji, Z., Sanz, S., Sevene, E., Soulaymani-Becheikh, R., Winstanley, P., Adjei, S., Anemana, S., Chandramohan, D., Issifou, S., Mockenhaupt F., F., Owusu-Agyei, S., Greenwood, B., Grobusch, M., Kremsner, P., Macete, E., Mshinda, H., Newman, R., Slutsker, L., Tanner, M., Alonso, P., Menendez, C. (2009). Efficacy and safety of intermittent preventive treatment with sulfadoxine-pyrimethamine for malaria in African infants: a pooled analysis of six randomised, placebo-controlled trials. The Lancet, 374(9700), 1533-1542. Available at: $\mathrm{http}: / /$ ecommons.aku.edu/eastafrica_fhs_mc_pathol/60 


\section{Authors}

J.J. Aponte, D. Schellenberg, A. Egan, A. Breckenridge, I. Carneiro, J. Critchley, I. Danquah, A. Dodoo, R. Kobbe, B. Lell, J. May, Zul Premji, S. Sanz, E. Sevene, R. Soulaymani-Becheikh, P. Winstanley, S. Adjei, S. Anemana, D. Chandramohan, S. Issifou, F. Mockenhaupt F., S. Owusu-Agyei, B. Greenwood, M.P. Grobusch, P.G. Kremsner, E. Macete, H. Mshinda, R.D. Newman, L. Slutsker, M. Tanner, P. Alonso, and C. Menendez 


\title{
Efficacy and safety of intermittent preventive treatment with sulfadoxine-pyrimethamine for malaria in African infants: a pooled analysis of six randomised, placebo-controlled trials
}

\author{
John J Aponte, David Schellenberg, Andrea Egan, Alasdair Breckenridge, Ilona Carneiro, Julia Critchley, Ina Danquah, Alexander Dodoo, \\ Robin Kobbe, Bertrand Lell, Jürgen May, Zul Premji, Sergi Sanz, Esperanza Sevene, Rachida Soulaymani-Becheikh, Peter Winstanley, Samuel Adjei, \\ Sylvester Anemana, Daniel Chandramohan, Saadou Issifou, Frank Mockenhaupt, Seth Owusu-Agyei, Brian Greenwood, Martin P Grobusch, \\ Peter G Kremsner, Eusebio Macete, Hassan Mshinda, Robert D Newman, Laurence Slutsker, Marcel Tanner, Pedro Alonso, Clara Menendez
}

\section{Summary}

Background Intermittent preventive treatment (IPT) is a promising strategy for malaria control in infants. We undertook a pooled analysis of the safety and efficacy of IPT with sulfadoxine-pyrimethamine in African infants.

Methods We pooled data from six double-blind, randomised, placebo-controlled trials (undertaken one each in Tanzania, Mozambique, and Gabon, and three in Ghana) that assessed the efficacy of IPT with sulfadoxinepyrimethamine in children. In all trials, IPT or placebo was given to children at the time of routine vaccinations delivered by WHO's Expanded Program on Immunization. Data from the trials for incidence of clinical malaria, risk of anaemia (packed-cell volume $<25 \%$ or haemoglobin $<80 \mathrm{~g} / \mathrm{L}$ [A: converted to SI units, ok?]), and incidence of hospital admissions and adverse events in infants up to 12 months of age were reanalysed by use of standard outcome definitions and time periods [A: ok?]. Analysis was by modified intention to treat, including all infants who received at least one dose of IPT or placebo. [A: please check that all edits in this section are correct]

Findings The six trials provided data on 7930 infants (IPT, $n=3958$; placebo, $n=3972$ ). IPT had a protective efficacy of $30 \cdot 3 \%(95 \%$ CI 19.8-39 - 4, p < $\cdot 0001)$ against clinical malaria, $21 \cdot 3 \%(8 \cdot 2-32 \cdot 5, \mathrm{p}=0 \cdot 002)$ against the risk of anaemia, $38 \cdot 1 \%(12 \cdot 5-56 \cdot 2, p=0 \cdot 007)$ against hospital admissions associated with malaria parasitaemia, and $22 \cdot 9 \%(10 \cdot 0-34 \cdot 0$ $\mathrm{p}=\mathbf{0} \cdot 001$ ) against all-cause hospital admissions. [A: edit ok?] There were 56 deaths in the ITP group compared with 53 in the placebo group (rate ratio $1 \cdot 05,95 \%$ CI $0 \cdot 72-1 \cdot 54, p=0 \cdot 79$ ). One death was judged possibly related to study treatment (IPT group). Four of 676 non-fatal hospital admissions in the IPT group were deemed related to study treatment compared with five of 860 in the placebo group. None of three serious dermatological adverse events in the IPT group were judged related to study treatment compared with one of 13 in the placebo group. [A: edits ok?]

Interpretation IPT with sulfadoxine-pyrimethamine in infants was safe and efficacious across a range of malaria transmission settings, suggesting that this intervention is a useful contribution to malaria control.

Funding Bill \& Melinda Gates Foundation.

\section{Introduction}

Plasmodium falciparum malaria is a major cause of disease and death in children in sub-Saharan Africa, and improved control measures are urgently needed. Intermittent preventive treatment (IPT) is the administration of a full course of an antimalarial drug at specified timepoints, whether or not parasites are present. Previous studies have shown that continuous chemoprophylaxis in infants reduces morbidity and mortality caused by malaria. However, this approach has not been implemented in endemic countries because of the major logistical challenges involved and fears that large-scale drug use would hasten the spread of drug resistance and impair the development of naturally acquired antimalarial immunity. ${ }^{1-5}$ Since IPT in infants is associated with lower drug exposure than is chemoprophylaxis, the effect of IPT on the spread of resistance and impairment of the development of immunity might also be lower. Furthermore, logistical challenges could be reduced by giving IPT to infants at the time of routine vaccinations delivered through WHO's Expanded Program on Immunization (EPI).

Sulfadoxine-pyrimethamine [A: Our house style is not to abbreviate drug names] could be useful for IPT in infants because this combination is available, affordable, well tolerated, and already recommended for IPT in pregnancy. ${ }^{6,7}$ The long half-life of sulfadoxinepyrimethamine could produce an extended prophylactic effect and enables the combination to be given as a single dose, which can be supervised. From 1999 to 2007, six randomised, placebo-controlled trials of IPT with sulfadoxine-pyrimethamine were completed..$^{8-13}$ These trials assessed the effect of three or four doses of IPT on malaria in early childhood. Since the study designs

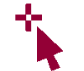

Lancet 2009; 374:

Barcelona Centre for International Health Research, Hospital Clinic, University of Barcelona, Barcelona, Spain (J) Aponte MD, A Egan PhD, S Sanz PhD, P Alonso MD, ( Menendez MD); London School of Hygiene and Tropical Medicine, London, UK (D Schellenberg MD, I Carneiro PhD, D Chandramohan MD, B Greenwood MD); Medicines and Healthcare Products Regulatory Agency, London, UK (A Breckenridge MD); Institute of Health and Society, Advancing Research in Chronic Disease Epidemiology (ARCHEPI) programme, School of Population and Health Sciences, University of Newcastle, Newcastle upon Tyne, UK (J Critchley PhD); Institute of Tropical Medicine and International Health, Charité-University Medicine Berlin, Berlin, Germany (I Danquah MD,

F Mockenhaupt MD); Centre for Tropical Clinical Pharmacology and Therapeutics, University of Ghana Medical School, KorleBu Teaching Hospital, Accra, Ghana (A Dodoo MD); Research Group Infectious Disease Epidemiology, Bernhard Nocht Institute for Tropical Medicine, Hamburg, Germany (R Kobbe MD, J May MD); Department of Parasitology, Institute of Tropical Medicine, University of Tübingen, Tübingen, Germany (B Lell MD, SIssifou MD, P G Kremsner MD); Medical Research Unit, Albert Schweitzer Hospital, Lambaréné, Gabon (B Lell, SIssifou, M P Grobusch MD, $P G$ Kremsner); Department of Parasitology/Medical Entomology, 
School of Public Health and Social Sciences, Muhimbili University College of Health Sciences, Dar es Salaam, Tanzania (Z Premji MD); Pharmacology Department of Eduardo Mondlane University, Faculty of Medicine, Maputo, Mozambique (E Sevene MD); Centre Anti-poisons et de Pharmacovigilance du Maroc, Rabat, Morocco

(R Soulaymani-Becheikh MD); School of Clinical Sciences, University of Liverpool, Liverpool, UK

(P Winstanley MD); Ministry of Health/Ghana Health Service, Agona, Ashanti Region, Ghana (S Adjei MD); Ministry of Health/Ghana Health Service,

Secondi-Takoradi, Western Region, Ghana

(S Anemana MD); Kintampo Health Research Centre, Ghana Health Service/Ministry of Health, Kintampo, Ghana (S Owusu-Agyei MD); Infectious Disease Unit, Division of Clinical Microbiology and Infectious Diseases, NHLS and Faculty of Health Sciences, University of Witwatersrand, Johannesburg, South Africa (M P Grobusch); Centro de Investigação em Saude de

Manhiça, Manhiça,

Mozambique (P Alonso,

E Macete MD); Ifakara Health Research Development Centre, Ifakara, Tanzania

(H Mshinda MD); Centers for Disease Control and

Prevention, Atlanta, GA, USA (R D Newman MD,

L Slutsker MD); and Swiss Tropical Institute, Basel, Switzerland (M Tanner MD) [A: please check affiliations carefully. Please note we state one qualification only per author). Please indicate any full professors]

Correspondence to:

Dr Marcel Tanner, Swiss Tropical Institute, Socinstrasse 57, PO Box

4002, Basel, Switzerland

marcel.tanner@unibas.ch

For more on the

IPTi Consortium see http:// www.ipti-malaria.org/

See Online for webappendix differed in terms of dosing schedule, primary endpoints, and duration of follow-up, we were unable to compare the trials using the published results. We therefore reanalysed the data using standardised outcome definitions and time periods to generate a meaningful pooled analysis of the safety and efficacy of IPT given to infants at the time of routine immunisation. We also investigated whether there was a potential increase in morbidity in the period after the intervention.

\section{Methods}

[A: please note, subheadings changed to conform with Lancet style]

\section{Search strategy and selection criteria}

This analysis was led by the IPTi Consortium, made up of autonomous research institutions, WHO, and UNICEF, and assembled to assess IPT in infants as a potential public health tool. ${ }^{14-16}$ [A: URL corrected, ok?] An independent consortium safety panel and a statistical working group (webappendix) were convened to undertake pooled analyses of safety and efficacy, respectively. In 2005, the IPTi Consortium invited the principal investigator of every completed or continuing trial of IPT with sulfadoxine-pyrimethamine in infants to take part in the pooled analyses. Trials were eligible for inclusion if they had randomly assigned asymptomatic children (younger than 1 year) who were attending routine health contacts to either IPT with sulfadoxine-pyrimethamine or placebo. [A: edit ok? Placebo had not been mentioned] We did not include trials of intermittent treatment that used different drugs, did not deliver IPT alongside EPI vaccinations, used IPT as a treatment for anaemia, or gave IPT at monthly intervals to schoolchildren or children less than 10 years of age in settings with highly seasonal transmission of malaria. These pooled analyses include all six eligible trials of IPT with sulfadoxinepyrimethamine in infants published up to May, 2009. ${ }^{8-13}$ A PubMed search for randomised controlled trials of infants 1-23 months old with the key words "intermittent", "treatment", "malaria", and "infants" did not find any additional studies that met our eligibility criteria.

\section{Patients, study design, and procedures}

The six randomised controlled trials, described in detail elsewhere, are summarised in table 1 and figure 1. [A: references have been renumbered so that they appear in order of mention in table 1 . Please check throughout carefully] The trials were undertaken in Ifakara in Tanzania, Manhiça in Mozambique, Lambaréné in Gabon, and Navrongo, Kumasi, and Tamale, in Ghana, and assessed the efficacy of IPT with sulfadoxinepyrimethamine for prevention of clinical malaria and anaemia during the first or second year of life, or both. Block randomisation by individual was done in all trials apart from the one in Navrongo, which was clusterrandomised by community. All trials were double-blind. [A: ok?]
The dosing schedule for IPT and placebo differed between the trials (figure 1). Doses of IPT were given according to bodyweight in the trials in Ifakara and Manhiça, according to dose number in the trial in Navrongo, and as a fixed dose in the trials in Kumasi, Lambaréné, and Tamale. One tablet contained $500 \mathrm{mg}$ sulfadoxine and $25 \mathrm{mg}$ pyrimethamine. All six trials had received ethical approval.

Safety and efficacy were assessed by passive clinical 10 surveillance in all trials. Additionally, active detection of malaria and anaemia was done every month in the trials in Lambaréné and Kumasi, and every 3 months in the trial in Tamale (figure 1); in Lambaréné, a blood sample was taken only if the child was febrile, whereas in Kumasi and Tamale, the sample was taken irrespective of the presence of symptoms. In the trial in Lambaréné, safety was reviewed 1 week after every dose; a blood sample was taken if the child was febrile. In the trial in Manhiça, safety assessment was enhanced by home visits 1 week after every dose, registration of dermatological complaints of children attending a health facility, and blood tests 1 month after the second dose of IPT or placebo [A: ok?]. In the trial in Navrongo, $20 \%$ of infants were visited within 4 weeks of IPT or placebo administration so that side-effects could be assessed.

Thick blood films were stained and read by use of standard procedures. Parasite density was calculated on the assumption of a mean [A: ok? Since average can mean medium or mean] of 8000 leucocytes per $\mu \mathrm{L}$ in all trials, apart from the one in Lambaréné, where a volumebased method was used. ${ }^{17}$

The presence of anaemia was determined by packedcell volume measured in microcapillary tubes in the trials in Ifakara, Navrongo, and Manhiça, and by haemoglobin concentration measured with a HemoCue photometer in the trials in Kumasi (HemoCue, Derbyshire, UK) and Tamale (HemoCue, Angelholm, Sweden). In the trial in Lambaréné, full blood counts were undertaken on an Abbott Cell-Dyn 3000 device (Abbott Diagnostics, Santa Clara, CA, USA). There is no accepted common definition of anaemia in children under 6 months of age; therefore, a cut-off that was common among trials was used (packed-cell volume $<25 \%$ or haemoglobin $<80 \mathrm{~g} / \mathrm{L}$ ).

\section{Statistical analysis}

An analytical plan was agreed by all investigators before the reanalysis started. Data were reanalysed at the individual level. To enable a pooled analysis, outcome and follow-up definitions were based on information common to all trials; therefore, results do not necessarily correspond with those in reports published for each study. Analysis was by modified intention to treat, including all children who received at least one dose of IPT or placebo up to the follow-up times defined in table 2 . We examined the effect of the IPT intervention during the 35 days after a dose to assess the prophylactic benefit of sulfadoxinepyrimethamine. We chose this interval because, according 


\begin{tabular}{|c|c|c|c|c|c|c|}
\hline & Ifakara $^{8}$ & Navrongo $^{9}$ & Manhiça ${ }^{10}$ & Kumasi $^{11}$ & Tamale $^{12}$ & Lambaréné $e^{13}$ \\
\hline Country & Tanzania & Ghana & Mozambique & Ghana & Ghana & Gabon \\
\hline Recruitment years & 1999-2000 & $2000-02$ & $2002-04$ & $2003-05$ & 2003 & 2002-04 \\
\hline Pattern of malaria transmission & Perennial & Highly seasonal & Perennial with seasonal peaks & $\begin{array}{l}\text { Perennial with seasonal } \\
\text { peaks }\end{array}$ & $\begin{array}{l}\text { Perennial with } \\
\text { seasonal peaks }\end{array}$ & $\begin{array}{l}\text { Perennial with } \\
\text { seasonal peaks }\end{array}$ \\
\hline $\begin{array}{l}\text { Insecticide-treated bednet use in trial } \\
\text { participants (n/N [\%]) [A1] }\end{array}$ & $\mathrm{nn} / \mathrm{NN}(67 \%)$ & nn/NN (18\%) & $\mathrm{nn} / \mathrm{NN}(0 \%)$ & $\mathrm{nn} / \mathrm{NN}(2 \%)^{*}$ & $\mathrm{nn} / \mathrm{NN}(3 \%) \dagger$ & $\mathrm{nn} / \mathrm{NN}(5 \%)$ \\
\hline $\begin{array}{l}\text { Official first-line treatment for } \\
\text { uncomplicated malaria }\end{array}$ & $\begin{array}{l}\text { Chloroquine or sulfadoxine- } \\
\text { pyrimethamine }\end{array}$ & Chloroquine & $\begin{array}{l}\text { Chloroquine and sulfadoxine- } \\
\text { pyrimethamine }\end{array}$ & Chloroquine & Chloroquine & Chloroquine \\
\hline $\begin{array}{l}\text { Actual drug used in trial [A: ok?] for } \\
\text { treatment of uncomplicated malaria }\end{array}$ & Sulfadoxine-pyrimethamine & Chloroquine & Quinine & $\begin{array}{l}\text { Amodiaquine and } \\
\text { artesunate }\end{array}$ & Artesunate & $\begin{array}{l}\text { Amodiaquine } \\
\text { and artesunate }\end{array}$ \\
\hline $\begin{array}{l}\text { Sulfadoxine-pyrimethamine in-vivo } \\
\text { failure at } 14 \text { days in symptomatic } \\
6-59-\text { month old children (\% [date } \\
\text { assessed] [A: ok?]) }\end{array}$ & $31 \%(1999-2000)$ & $22 \%(2004)$ & $21 \%(2001)$ & Not available & $14 \%(2002)$ & $21 \%(2004)$ \\
\hline Iron supplementation & Unsupervised & Unsupervised & None & None & None & None \\
\hline $\begin{array}{l}\text { HIV prevalence (not measured in trial } \\
\text { participants or their mothers, } \% \text { ) }\end{array}$ & $6 \%$ in ANCs in Ifakara & About $2 \%$ in ANCs & $23 \%$ in ANCs in Manhiça & $2.7 \%$ in ANCs & $\begin{array}{l}\text { About } 2-3 \% \text { in } \\
\text { ANCs }\end{array}$ & $\begin{array}{l}7 \cdot 5 \%[\mathrm{~A}: \text { in } \\
\text { which } \\
\text { population?] }\end{array}$ \\
\hline Randomisation & Individual & Cluster & Individual & Individual & Individual & Individual \\
\hline $\begin{array}{l}\text { Dose of IPT with sulfadoxine- } \\
\text { pyrimethamine } \neq\end{array}$ & $\begin{array}{l}\text { According to bodyweight } \\
(<5 \mathrm{~kg} \text {, quarter of a tablet; } \\
5-10 \mathrm{~kg} \text {, half a tablet; }>10 \mathrm{~kg} \text {, } \\
\text { one tablet })\end{array}$ & $\begin{array}{l}\text { According to dose number } \\
\text { (half a tablet for first and } \\
\text { second doses, one tablet for } \\
\text { third and fourth doses) }\end{array}$ & $\begin{array}{l}\text { According to bodyweight } \\
(<5 \mathrm{~kg} \text {, quarter of a tablet; } \\
5-10 \mathrm{~kg} \text {, half a tablet; }>10 \mathrm{~kg} \text {, } \\
\text { one tablet })\end{array}$ & $\begin{array}{l}\text { Fixed (half a tablet at } \\
\text { each dose) }\end{array}$ & $\begin{array}{l}\text { Fixed (half a } \\
\text { tablet at each } \\
\text { dose) }\end{array}$ & $\begin{array}{l}\text { Fixed (half a } \\
\text { tablet at each } \\
\text { dose) }\end{array}$ \\
\hline Passive case detection & Yes & Yes & Yes & Yes & Yes & Yes \\
\hline Active case detection & No & No & No & Monthly & $\begin{array}{l}\text { Every } \\
3 \text { months }\end{array}$ & Monthly \\
\hline \multicolumn{7}{|l|}{$\begin{array}{l}\text { Number of children (modified } \\
\text { ITT population) }[\text { [A1] }\end{array}$} \\
\hline IPT & 350 & 1221 & 748 & 535 & 600 & 504 \\
\hline Placebo & 351 & 1225 & 755 & 535 & 599 & 507 \\
\hline $\begin{array}{l}\text { Incidence of clinical malaria } \\
\text { (episodes per person-years at risk) } \boldsymbol{\Phi}\end{array}$ & 0.54 & $1 \cdot 10$ & 0.79 & $1 \cdot 27$ & 0.95 & 0.16 \\
\hline $\begin{array}{l}\text { Risk of anaemia (of the first or only } \\
\text { episode, \%)\| }\end{array}$ & $8.6 \%$ & $6 \cdot 3 \%$ & $10 \cdot 6 \%$ & $37 \cdot 6 \%$ & $31 \cdot 7 \%$ & $15 \cdot 7 \%$ \\
\hline \multicolumn{7}{|c|}{ 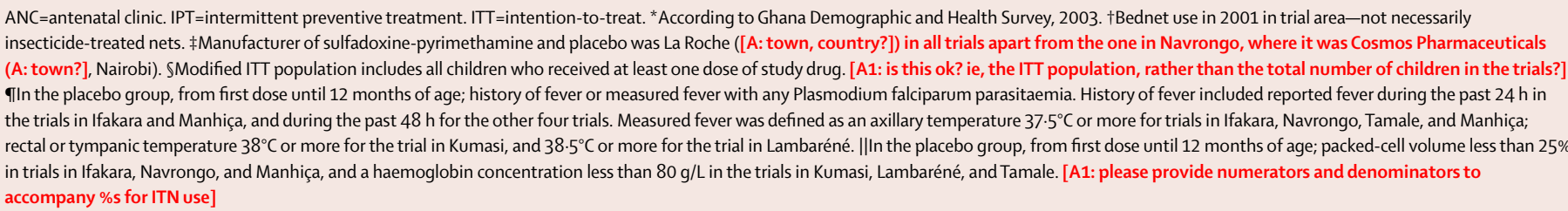 } \\
\hline
\end{tabular}

to the elimination half-life reported by the manufacturer, residual sulfadoxine plasma concentrations after 5 weeks are less than $5 \%$, which is consistent with negligible inhibitory activity. ${ }^{18}$ [A: please mention that the potential rebound effect was examined, and why]

Negative binomial regression, which allows for potential clustering of episodes within individuals, was used to investigate the effect of IPT on the incidence of all episodes of clinical malaria, clinical malaria with a locally sensitive case definition, ${ }^{19}$ all-cause hospital admissions, and hospital admissions associated with microscopically confirmed [A: correct?] malaria parasitaemia. To allow for clustering across individuals within the trial in Navrongo, 5 robust SEs were used. Incidence was calculated as the number of episodes divided by the time at risk (for definitions see table 2). [A:is this ok to add here?] Infants were not deemed at risk for 21 days after a clinical malaria episode, hospital admission, or receipt of an antimalarial treatment. This 21-day period was selected to avoid overlap with the 28-day period for active detection visits in the trials in Kumasi and Lambaréné. The effect of IPT on the relative risk of at least one episode of anaemia, with as the denominator the number of children at risk from the first dose until 12 months of age, was analysed by use of a Poisson regression model, with log-link and a robust error variance. ${ }^{20}$

The efficacy of IPT was defined as $(1-R R) \times 100$, where $5 \mathrm{RR}$ is the relative rate or relative risk [A: since relative risk can mean rate ratio or risk ratio, please define which is used]. Combined estimates were obtained by meta- 


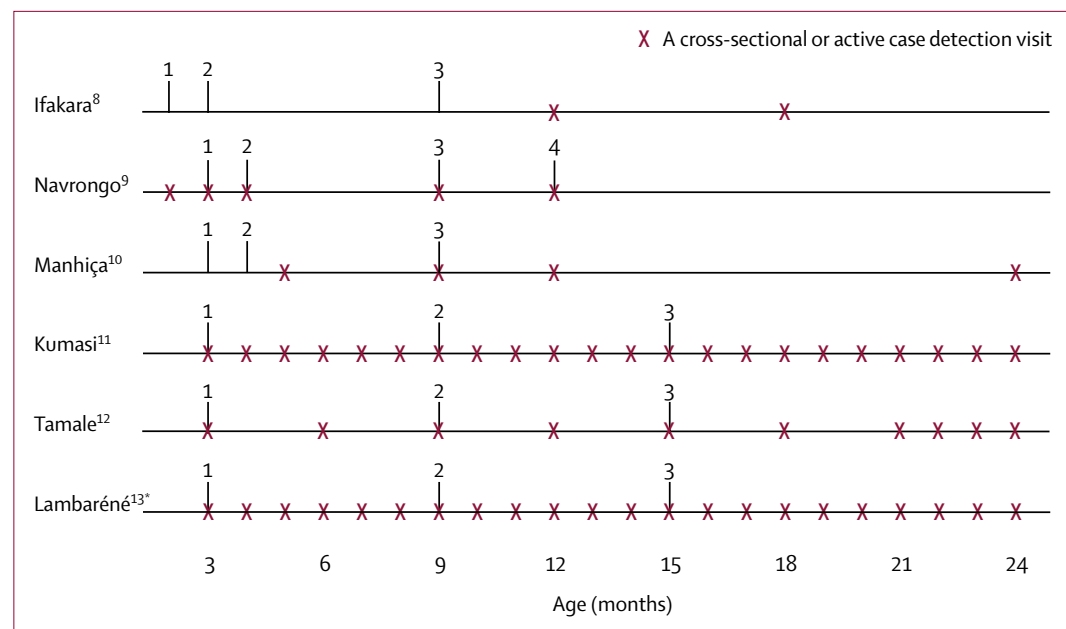

Figure 1: Schedules of study treatment and follow-up visits

Vertical bars represent the age when intermittent preventive treatment with sulfadoxine-pyrimethamine or placebo was given (and number of dose). *Follow-up in the trial in Lambaréné was up to 30 months of age.

analysis with random effects, and as weight for each trial the inverse of the $\mathrm{SE}$ of the estimated $\mathrm{RR}$ in the logarithmic scale. To assess the effect of an individual trial in the meta-analysis, sensitivity analyses were done in which one study at a time was removed from the analysis. Analyses were done with Stata version xx software. [A: version number?]

Standard WHO definitions were used for adverse events and for the grading of severity. ${ }^{21}$ In all trials apart from the one in Kumasi, a serious adverse event was defined as a hospital admission or death. In the trial in Kumasi, a life-threatening event or enduring disability was also judged as a serious adverse event (in the other trials, a patient with a life-threatening event would be admitted to hospital [A: edit ok?]). Assessment of causality was made by the on-site principal investigator or physician. Causality was assessed on symptoms known to be related to sulfadoxine-pyrimethamine, apart from in the trial in Kumasi where all adverse events that occurred within 8 weeks of treatment were deemed possibly related to study drug. Serious adverse events that occurred more than 3 months after the last dose of study drug were deemed very unlikely to be related to treatment and excluded from these analyses.

The number of deaths, non-fatal hospital admissions, serious dermatological adverse events [A: why were only 0 dermatological adverse events analysed?], total sample size, and person-time at risk were extracted by principal investigators or statisticians and reviewed by the consortium safety panel. A meta-analysis was done on the risk of mortality by use of Review Manager version 55.0 or StatsDirect version 2.7.1 software. The numerator was the number of deaths, and the denominator was the number of infants who received at least one dose of IPT or placebo [A: ok?]. The pooled rate ratio was calculated by the DerSimonian-Laird method. For the trial that was 20 cluster randomised, the rate ratio and SE of the rate ratio were estimated by use of a robust cluster method. The cluster-adjusted SE was identical to the unadjusted SE.

Heterogeneity between trials was assessed by visual inspection of forest plots of the effects and 95\% CIs for each site, calculation of a $\chi^{2}$ test for heterogeneity (statistical significance at $10 \%$ level), and calculation of the $I^{2}$ statistic (which quantifies the amount of heterogeneity over and above that expected due to chance alone on a scale from $0 \%$ to $100 \%) .{ }^{22}$ Fixed-effect meta-analysis was used to pool data for this outcome measure.

\section{Role of the funding source}

The sponsor of the study had no role in study design, data collection, data analysis, data interpretation, or writing of the report. The corresponding author had full access to all the data in the study and had final responsibility for the decision to submit for publication.

\begin{tabular}{|c|c|c|}
\hline & Start of time at risk & End of time at risk \\
\hline \multicolumn{3}{|c|}{ Efficacy (clinical malaria, hospital admissions, anaemia) } \\
\hline Primary & Dose 1 of IPT or placebo & 12 months of age \\
\hline Secondary & Dose 1 of IPT or placebo & 3 months after the last dose of IPT or placebo \\
\hline Prophylactic effect I & Dose of IPT or placebo at 3 months of age ${ }^{*}$ & 35 days after start of time at risk \\
\hline Prophylactic effect II & Dose of IPT or placebo at 9 months of age $\dagger$ & 35 days after start of time at risk \\
\hline Prophylactic effect III & Dose of IPT or placebo at 12 months or 15 months of age $\ddagger$ & 35 days after start of time at risk \\
\hline Inter-dose effect & 35 days after the dose of IPT or placebo at 3 or 4 months of age & Dose of IPT or placebo at 9 months of age \\
\hline Potential rebound I & 35 days after the dose of IPT or placebo at 9 months of age & 15 months of age or the next dose of IPT or placebo $\$$ \\
\hline Potential rebound II & 35 days after the last dose of IPT or placebo & 5 months after start of time at risk \\
\hline \multicolumn{3}{|c|}{ Safety (deaths, adverse effects) } \\
\hline Primary & Dose 1 of IPT or placebo & 3 months after the last dose given or 12 months of age \\
\hline \multicolumn{3}{|c|}{$\begin{array}{l}\text { IPT=intermittent preventive treatment. * Dose } 2 \text { in the trial in Ifakara, dose } 1 \text { in the other trials. †Dose } 3 \text { in the trials in Ifakara, Navrongo, and Manhiça; dose } 2 \text { in the trials in } \\
\text { Kumasi, Tamale, and Lambaréné. ‡Dose } 4 \text { in the trial in Navrongo at } 12 \text { months; dose } 3 \text { in the trials in Kumasi, Tamale, and Lambaréné at } 15 \text { months of age. SNext dose at } \\
12 \text { months of age in the trial in Navrongo, and } 15 \text { months of age in the trials in Kumasi, Tamale, and Lambaréné. TLast dose was at } 9 \text { months of age in the trials in Ifakara and } \\
\text { Manhiça, at } 12 \text { months of age in the trial in Navrongo, and at } 15 \text { months of age in the trials in Kumasi, Tamale, and Lambaréné. [A: "or placebo" added to all—ok?] }\end{array}$} \\
\hline
\end{tabular}




\begin{tabular}{|c|c|c|c|c|c|c|}
\hline & Ifakara $^{8}$ & Navrongo $^{9}$ & Manhiça ${ }^{10}$ & Kumasi $^{11}$ & Tamale $^{12}$ & Lambaréné ${ }^{13}$ \\
\hline \multicolumn{7}{|l|}{ From dose 1 until 12 months of age } \\
\hline \multicolumn{7}{|l|}{ Clinical malaria } \\
\hline Primary definition* & $59 \cdot 4 \%(41 \cdot 7$ to $71 \cdot 7)$ & $30.3 \%$ (17.8 to 40.9$)$ & $20.8 \%(3.5$ to 35.0$)$ & $20 \cdot 7 \%(8 \cdot 7$ to $31 \cdot 2)$ & $32 \cdot 4 \%(19 \cdot 6$ to $43 \cdot 2)$ & $22 \cdot 6 \%(-24 \cdot 2$ to $51 \cdot 7)$ \\
\hline Locally defined cut-off density $\dagger$ & $61 \cdot 9 \%(43 \cdot 5$ to $74 \cdot 3)$ & $32 \cdot 3 \%$ (16.9 to $44 \cdot 8)$ & $30.9 \%(14 \cdot 4$ to $44 \cdot 3)$ & $22 \cdot 7 \%(9 \cdot 2$ to $34 \cdot 1)$ & $27 \cdot 4 \%(4 \cdot 7$ to $44 \cdot 6)$ & $29 \cdot 2 \%(-15 \cdot 1$ to $56 \cdot 5)$ \\
\hline High-density cut-off $\neq$ & $56 \cdot 3 \%(25 \cdot 3$ to $74 \cdot 5)$ & $33 \cdot 2 \%$ (14.0 to $48 \cdot 1)$ & $26.6 \%(6.5$ to 42.4$)$ & $18 \cdot 4 \%(-15 \cdot 1$ to $42 \cdot 2)$ & $26.0 \%(-22.0$ to 55.1$)$ & $26 \cdot 2 \%(-49 \cdot 0$ to $63 \cdot 5)$ \\
\hline All-cause hospital admissions & $29.0 \%(6.6$ to $46 \cdot 1)$ & $18 \cdot 3 \%(0 \cdot 3$ to $33 \cdot 1)$ & $24.9 \%(6.6$ to 39.7$)$ & $17.8 \%(-22.5$ to 44.8$)$ & $49.8 \%(18.5$ to 69.0$)$ & $-35 \cdot 8 \%(-142 \cdot 3$ to $23 \cdot 9)$ \\
\hline $\begin{array}{l}\text { Hospital admissions associated } \\
\text { with malaria parasitaemias }\end{array}$ & $58 \cdot 3 \%$ (28.4 to $75 \cdot 8)$ & $52 \cdot 1 \%(29.5$ to 67.5$)$ & $20 \cdot 3 \%(-19.9$ to $47 \cdot 0)$ & $-6 \cdot 6 \%(-103 \cdot 1$ to $44 \cdot 1)$ & $44 \cdot 5 \%(-80 \cdot 1$ to $82 \cdot 9)$ & .. \\
\hline $\begin{array}{l}\text { Anaemia (reduced risk of first or } \\
\text { only episode) } \boldsymbol{\uparrow}\end{array}$ & $49.9 \%$ (8.4 to 72.5$)$ & $46 \cdot 5 \%(21 \cdot 2$ to $63 \cdot 7)$ & $5 \cdot 4 \%(-27 \cdot 5$ to $29 \cdot 8)$ & $11 \cdot 1 \%(-4 \cdot 5$ to $24 \cdot 4)$ & $17.0 \%(0.8$ to 30.5$)$ & $25 \cdot 2 \%(-2 \cdot 7$ to $45 \cdot 5)$ \\
\hline \multicolumn{7}{|c|}{ Against clinical malaria (primary definition) on different follow-up times } \\
\hline \multicolumn{7}{|l|}{ Prophylactic effect|| } \\
\hline I (after dose at 3 months of age) & $77 \cdot 7 \%(-3 \cdot 0$ to $95 \cdot 2)$ & $75 \cdot 6 \%$ (49.6 to $88 \cdot 2)$ & $57 \cdot 5 \%(20.6$ to $77 \cdot 3)$ & $82.0 \%(61.8$ to $91 \cdot 5)$ & $83.0 \%(12.8$ to $96 \cdot 7)$ & $74 \cdot 8 \%(-125 \cdot 5$ to $97 \cdot 2)$ \\
\hline II (after dose at 9 months of age) & $91 \cdot 1 \%$ (62.1 to $97 \cdot 9)$ & $79 \cdot 3 \%$ (69.5 to 85.9$)$ & $65 \cdot 2 \%(37 \cdot 1$ to $80 \cdot 7)$ & $47 \cdot 6 \%(17 \cdot 1$ to $66 \cdot 8)$ & $97.6 \%(90.5$ to 99.4$)$ & $72 \cdot 9 \%(-53 \cdot 2$ to $95 \cdot 2)$ \\
\hline $\begin{array}{l}\text { III (after dose at } 12 \text { or } 15 \text { months } \\
\text { of age) }\end{array}$ &. & $73.7 \%$ (57.6 to 83.7$)$ & .. & $29 \cdot 7 \%(-5 \cdot 1$ to $52 \cdot 9)$ & $90 \cdot 6 \%(79 \cdot 7$ to $95 \cdot 6)$ & $77.5 \%(-100 \cdot 9$ to 97.5$)$ \\
\hline Inter-dose effect period ${ }^{* *}$ & $42 \cdot 4 \%(-1 \cdot 2$ to $67 \cdot 3)$ & $12.9 \%(-6.8$ to 29.0$)$ & $-8 \cdot 0 \%(-39 \cdot 3$ to $16 \cdot 3)$ & $11 \cdot 5 \%(-6 \cdot 1$ to $26 \cdot 2)$ & $19 \cdot 6 \%(-0.2$ to $35 \cdot 5)$ & $11 \cdot 2 \%(-62 \cdot 9$ to $51 \cdot 6)$ \\
\hline Potential rebound period $\mathrm{I \dagger \dagger}$ & $29 \cdot 0 \%(-4 \cdot 2$ to $51 \cdot 6)$ & $-3 \cdot 4 \%(-29 \cdot 3$ to $17 \cdot 5)$ & $7 \cdot 4 \%(-13 \cdot 4$ to $24 \cdot 4)$ & $7 \cdot 8 \%(-9 \cdot 1$ to $22 \cdot 1)$ & $19 \cdot 6 \%(-2 \cdot 2$ to $36 \cdot 7)$ & $12 \cdot 7 \%(-54 \cdot 9$ to $50 \cdot 8)$ \\
\hline \multicolumn{7}{|l|}{ Potential rebound period II¥¥ } \\
\hline Clinical malaria (primary definition) & $30.3 \%(1.0$ to 50.9$)$ & $0 \cdot 2 \%(-20 \cdot 3$ to $17 \cdot 1)$ & $-11 \cdot 0 \%(-45 \cdot 0$ to $15 \cdot 0)$ & $-5.8 \%(-24 \cdot 0$ to 9.8$)$ & $-0.3 \%(-18.9$ to 15.4$)$ & $-36 \cdot 3 \%(-147 \cdot 3$ to $24 \cdot 9)$ \\
\hline All-cause hospital admissions & $-7 \cdot 9 \%(-51 \cdot 9$ to $23 \cdot 4)$ & $-16 \cdot 5 \%(-54 \cdot 0$ to $11 \cdot 9)$ & $8 \cdot 4 \%(-25 \cdot 6$ to $33 \cdot 2)$ & $-19.8 \%(-108.0$ to $31 \cdot 0)$ & $24 \cdot 6 \%(-21 \cdot 5$ to $53 \cdot 3)$ & $-1 \cdot 4 \%(-115 \cdot 7$ to $52 \cdot 3)$ \\
\hline $\begin{array}{l}\text { Hospital admissions associated } \\
\text { with malaria parasitaemia }\end{array}$ & $11 \cdot 3 \%(-74 \cdot 4$ to $54 \cdot 9)$ & $-8 \cdot 6 \%(-79 \cdot 5$ to $34 \cdot 3)$ & $-36 \cdot 1 \%(-117 \cdot 4$ to $14 \cdot 8)$ & $-47 \cdot 7 \%(-261 \cdot 2$ to $39 \cdot 6)$ & $-74 \cdot 5 \%(-496 \cdot 1$ to $48 \cdot 9)$ & \\
\hline $\begin{array}{l}\text { Anaemia (reduced risk of first or } \\
\text { only episode) }\end{array}$ & $40 \cdot 0 \%(-11 \cdot 8$ to $67 \cdot 8)$ & $-24 \cdot 2 \%(-105 \cdot 0$ to $26 \cdot 3)$ & $10 \cdot 8 \%(-36 \cdot 4$ to $41 \cdot 7)$ & $-2 \cdot 5 \%(-22 \cdot 9$ to $14 \cdot 6)$ & $3 \cdot 4 \%(-9 \cdot 9$ to $15 \cdot 1)$ & $-15 \cdot 1 \%(-154 \cdot 3$ to $47 \cdot 9)$ \\
\hline \multicolumn{7}{|c|}{ 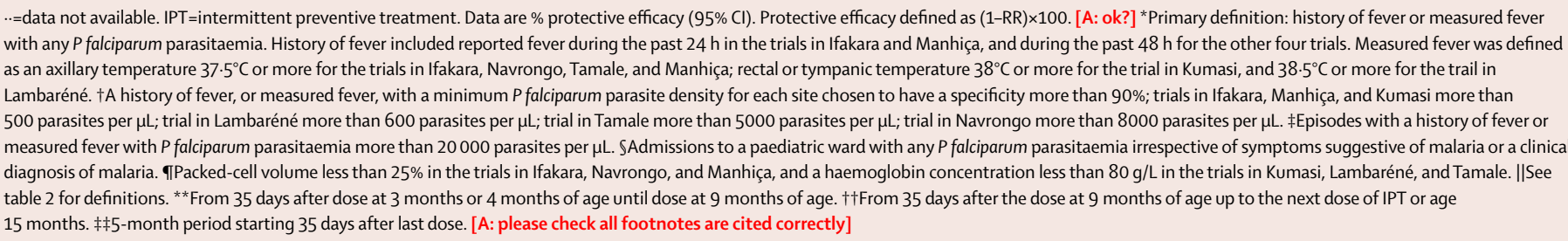 } \\
\hline
\end{tabular}

\section{Results}

[A: to conform with journal style, subheadings have been deleted from this section. Also, to avoid repetition, any 40 data in the text that is clearly shown in the tables and figures has been deleted]

This analysis is based on data from 7930 infants (IPT, $\mathrm{n}=3958$; placebo, $\mathrm{n}=3972$ ) in all six trials of IPT with sulfadoxine-pyrimethamine in infants published up to 45 May, 2009. Reported baseline characteristics were similar between IPT and placebo groups in all the trials. [A: please provide a table showing the baseline characteristics of the two groups]

Table 3 shows the estimates of efficacy of IPT in infants 50 up to 12 months of age in the individual trials. The combined estimate of protective efficacy against the primary definition of clinical malaria in children aged up to 12 months was $30 \cdot 3 \%$ (95\% CI $19 \cdot 8-39 \cdot 4$, p $<0.0001$; figure 2 and table 4). There was significant heterogeneity 5 between trials $\left(I^{2}=61 \cdot 8 \%\right)$. Removal of the trial with the highest protective efficacy (Ifakara) reduced heterogeneity to non-significant levels, and the combined efficacy estimate to $25.9 \%(19 \cdot 6-31.7 \%, \mathrm{p}<0.001$; table 4). [A: please provide exact $p$ value unless $p<0 \cdot 0001]$ Detailed information about each analysis, including the total number of events and person-years at risk, total number of children in each site and outcome, as well as other analyses are provided in the webappendix.

The effect of IPT on the relative risk of anaemia in infants ranged from $5.4 \%$ to $49.9 \%$, with moderate heterogeneity between trials $\left(I^{2}=46 \cdot 9 \%\right)$. The combined efficacy estimate for risk of anaemia was $21.3 \%$ $(8 \cdot 2-32 \cdot 5, \mathrm{p}=0 \cdot 002$; table 4$)$.

IPT had protective efficacies of $22.9 \%(10 \cdot 0-34 \cdot 0$, $\mathrm{p}=0.001)$ against all-cause hospital admissions and $38 \cdot 1 \%(12 \cdot 5-56 \cdot 2, \mathrm{p}=0 \cdot 007)$ and for hospital admissions associated with malaria parasitaemia (table 4). The heterogeneity between trials for these two outcomes was moderate $\left(I^{2}=33 \cdot 5 \%\right.$ and $49 \cdot 6 \%$, respectively); however, removing the trial with the highest protective efficacy made little difference to the estimates (table 4). 


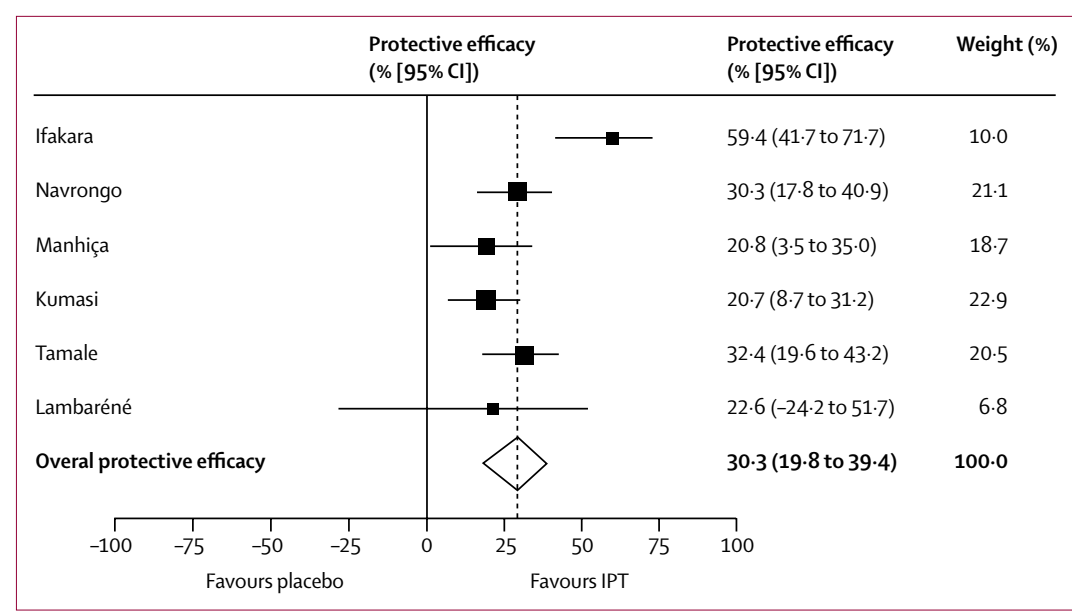

Figure 2: Combined estimates for the protective efficacy of IPT with sulfadoxine-pyrimethamine in infants against clinical malaria from dose 1 up to 12 months of age

The width of the diamond represents the $95 \% \mathrm{Cl}$ interval in the overall pooled protective efficacy estimate. [A: vertical line moved to $0 \%$. Ok?]
1 condition but died the next night at home. The most probable cause of death was sepsis with complications of recent malaria and severe anaemia.

Four of 676 non-fatal hospital admissions in the IPT 5 group were deemed related to study treatment (assigned while the trials were masked), compared with five of 860 in the placebo group. [A: edit ok?] In the trial in Kumasi, causality could not be assessed for five hospital admissions (IPT, $\mathrm{n}=3$; placebo, $\mathrm{n}=2$ ) because hospital 10 files were missing.

Three serious dermatological adverse events were reported in the IPT group; however, none of these was judged related to study treatment (table 5). Of 13 serious dermatological adverse events in the placebo group, one 5 was classified as possibly related to study drug, since it occurred within 3 weeks after a dose. At the time of the second dose of study treatment at 9 months of age, the infant had malaria and received artesunate-amodiaquine (in addition to study treatment) but was not admitted to 20 hospital. The infant developed bullous skin lesions 3 weeks later. Another infant in the placebo group was diagnosed with Stevens-Johnson syndrome and died at the age of 5 months from multiple organ failure, 2 months after the first dose of study treatment. The infant was HIV-positive and had been started on agents known to be associated with Stevens-Johnson syndrome (antituberculosis drugs [isoniazid, rifampicin, pyrazinamide, and ethambutol] and co-trimoxazole) 5 days before the onset of dermatological symptoms. The 30 child had not been admitted to hospital. placebo group during prophylactic effects II and III, respectively. [A: is this edit correct?] Analyses of the interdose effect ( 35 days after the IPT or placebo dose at 3 or 4 months of age until the dose at 9 months of age) varied between trials with borderline significant efficacy in the trials in Ifakara and Tamale, but no effect was seen in the other trials.

Incidence of clinical malaria and hospital admissions and the risk of anaemia did not differ between groups in either of the potential rebound periods (tables 3 and 4, see table 2 for definitions). [A: edit ok?] Similar results were found in the sensitivity analysis (table 4).

There were 56 deaths $(1.4 \%)$ in the IPT group compared with $53(1.3 \%)$ in the placebo group (rate ratio 1.05, 95\% CI $0 \cdot 72-1 \cdot 54, p=0 \cdot 79)$. There was moderate statistical heterogeneity in the number of deaths between trials $\left(I^{2}=24 \cdot 6 \%\right)$. One death, in the IPT group of the trial in Kumasi, was classified as possibly caused by study treatment [A: ok, rather than IPT? Were assignment groups still masked when classified?], since it occurred 19 days after a treatment dose (table 5). At the visit after administration of the second dose at 9 months of age, malaria was confirmed by microscopy and the infant received amodiaquine, and iron and folic acid supplementation. 2 weeks later, the infant became very weak, was admitted to hospital, given a blood transfusion for severe anaemia, and received penicillin, artesunate, paracetamol, iron, and folic acid. The infant was discharged 6 days later in an apparently satisfactory

\section{Discussion}

[A: any repetition of Introduction and Results sections has been deleted] This pooled analysis of six randomised, 35 placebo-controlled trials showed that the incidence of clinical malaria and hospital admissions and the risk of anaemia were lower in infants assigned to ITP with sulfadoxine-pyrimethamine than in those assigned to placebo. Other trials of intermittent treatment were not 40 included in this analysis because they used different drugs and did not deliver IPT at the same time as EPI vaccines, ${ }^{23}$ used IPT as a treatment for anaemia in children, ${ }^{24,25}$ or gave IPT with monthly intervals to schoolchildren $^{26}$ or children up to 5 years or 10 years of age in settings with highly seasonal transmission of malaria. ${ }^{27-29}[\mathrm{~A}$ : edit ok (ie, were the schoolchildren in ref 26 given IPT at monthly intervals)?]

None of the individual trials had sufficient power to assess the effect of IPT on mortality. However, our metaanalysis found that the overall number of deaths did not differ between groups, suggesting that IPT does not reduce mortality compared with placebo. All the studies provided study participants with good access to curative services, which, combined with intensive follow-up in some studies, might account for the low crude mortality rates recorded in the trials. Our efficacy estimates might therefore underestimate the potential effect of IPT on 


\begin{tabular}{|c|c|c|c|c|c|c|c|c|c|c|c|c|}
\hline & \multicolumn{3}{|c|}{ Placebo } & \multicolumn{3}{|l|}{ IPT } & \multicolumn{3}{|l|}{ Combined estimates } & \multicolumn{3}{|l|}{ Sensitivity analysis $₫$} \\
\hline & Events & PYAR $^{*}$ & $\begin{array}{l}\text { Incidence } \\
\text { per PYAR }\end{array}$ & Events & PYAR $^{*}$ & $\begin{array}{l}\text { Incidence } \\
\text { per PYAR }\end{array}$ & $\begin{array}{l}\text { Pooled estimate of } \\
\text { protective efficacy }{ }^{\prime} \\
(\%[95 \% \mathrm{Cl}])\end{array}$ & $12 \ddagger$ & $\mathrm{p}$ value & $\begin{array}{l}\text { Pooled estimate of } \\
\text { protective efficacy } \dagger \\
(\%[95 \% \mathrm{CI})\end{array}$ & p value & Trial removed \\
\hline \multicolumn{13}{|c|}{ From dose 1 until 12 months of age } \\
\hline \multicolumn{13}{|l|}{ Clinical malaria } \\
\hline Primary definition $\mathbb{T}$ & 2257 & 2598 & 0.87 & 1658 & 2625 & 0.63 & $30.3 \%(19.8$ to $39 \cdot 4)$ & 61.8 & $<0.0001$ & $25.9 \%(19 \cdot 6,31 \cdot 7)$ & $? ?$ & Ifakara $^{8}$ \\
\hline $\begin{array}{l}\text { Locally defined cut- } \\
\text { off densityl| }\end{array}$ & 1473 & 2632 & 0.56 & 1048 & 2651 & 0.40 & $32.9 \%(21.8$ to 42.4$)$ & $53 \cdot 7$ & $? ?$ & $27.7 \%$ (20.2 to 34.5$)$ & $? ?$ & Ifakara $^{8}$ \\
\hline High-density cut-off ${ }^{\star * *}$ & 656 & 2671 & 0.25 & 467 & 2684 & 0.17 & $29.9 \%(19 \cdot 3$ to $39 \cdot 1)$ & 0 & $? ?$ & $27 \cdot 4 \%(16 \cdot 1$ to $37 \cdot 3)$ & $? ?$ & Ifakara $^{8}$ \\
\hline $\begin{array}{l}\text { All-cause hospital } \\
\text { admissions }\end{array}$ & 898 & 2776 & 0.32 & 714 & 2783 & 0.26 & $22.9 \%(10.0$ to 34.0$)$ & $33 \cdot 5$ & 0.001 & $20.6 \%(9.8$ to 30.1$)$ & $? ?$ & Tamale $^{12}$ \\
\hline $\begin{array}{l}\text { Hospital admissions } \\
\text { associated with malaria } \\
\text { parasitaemiat† }\end{array}$ & 233 & 2477 & 0.09 & 141 & 2480 & 0.06 & $38.1 \%(12.5$ to $56 \cdot 2)$ & $49 \cdot 6$ & 0.007 & $31 \cdot 4 \%(-0.4$ to $53 \cdot 1)$ & $? ?$ & Ifakara $^{8}$ \\
\hline $\begin{array}{l}\text { Anaemia (reduced risk of } \\
\text { first or only episode) } \neq \neq\end{array}$ & 656 & 3963 & $0 \cdot 17$ & 526 & 3948 & 0.13 & $21.3 \%(8.2$ to 32.5$)$ & $46 \cdot 9$ & 0.002 & $18 \cdot 7 \%(6 \cdot 2$ to $29 \cdot 5)$ & $? ?$ & Ifakara $^{8}$ \\
\hline \multicolumn{13}{|c|}{ Against clinical malaria (primary definition) on different follow-up times } \\
\hline \multicolumn{13}{|l|}{ Prophylactic effect\$s } \\
\hline $\begin{array}{l}\text { I (after dose at } \\
3 \text { months of age) }\end{array}$ & 152 & 341 & 0.45 & 42 & 344 & 0.12 & $73.1 \%$ (60.9 to 81.4$)$ & 0 & $? ?$ & $72 \cdot 4 \%(59.6$ to $81 \cdot 2)$ & $? ?$ & Tamale $^{12}$ \\
\hline $\begin{array}{l}\text { II (after dose at } \\
9 \text { months of age) }\end{array}$ & 309 & 307 & 1.00 & 87 & 323 & 0.27 & $79 \cdot 7 \%$ (60.1 to $89 \cdot 7)$ & $79 \cdot 8$ & $? ?$ & $71.3 \%$ (51.0 to 83.2$)$ & $? ?$ & Tamale $^{12}$ \\
\hline $\begin{array}{l}\text { III (after dose at } 12 \text { or } \\
15 \text { months of age) }\end{array}$ & 237 & 207 & 1.14 & 95 & 224 & 0.42 & $73.5 \%$ (31.3 to 89.8$)$ & 87.6 & $? ?$ & $59.8 \%(5.4$ to 82.9$)$ & $? ?$ & Tamale $^{12}$ \\
\hline $\begin{array}{l}\text { Inter-dose effect } \\
\text { periodøף }\end{array}$ & 1185 & 1294 & 0.92 & 1054 & 1298 & 0.81 & $12 \cdot 1 \%(2 \cdot 2$ to $21 \cdot 0)$ & $5 \cdot 7$ & $? ?$ & $10.8 \%(1 \cdot 1$ to $19 \cdot 6)$ & $? ?$ & Ifakara $^{8}$ \\
\hline $\begin{array}{l}\text { Potential rebound } \\
\text { period IIIII }\end{array}$ & 1264 & 1405 & 0.90 & 1166 & 1415 & 0.82 & $9.5 \%(0.3$ to 17.8$)$ & 0 & 0.044 & $8.0 \%(-1 \cdot 7$ to $16 \cdot 7)$ & $? ?$ & Ifakara $^{8}$ \\
\hline \multicolumn{13}{|c|}{ Potential rebound period $I^{* * *}$} \\
\hline $\begin{array}{l}\text { Clinical malaria } \\
\text { (primary definition) }\end{array}$ & 1491 & 1368 & 1.09 & 1502 & 1370 & $1 \cdot 10$ & $-1.0 \%(-11.9$ to $8 \cdot 7)$ & 18 & 0.843 & $-3 \cdot 9 \%(-13 \cdot 9$ to $5 \cdot 2)$ & $? ?$ & Ifakara $^{8}$ \\
\hline $\begin{array}{l}\text { All-cause hospital } \\
\text { admissions }\end{array}$ & 404 & 1408 & 0.29 & 413 & 1470 & 0.28 & $-2 \cdot 7 \%(-20 \cdot 2$ to $12 \cdot 1)$ & 0 & 0.735 & $-6 \cdot 6 \%(-25 \cdot 9$ to 9.6$)$ & $? ?$ & Tamale $^{12}$ \\
\hline $\begin{array}{l}\text { Hospital admissions } \\
\text { associated with malaria } \\
\text { parasitaemia }\end{array}$ & 105 & 1308 & 0.08 & 124 & 1302 & $1 \cdot 0$ & $-20 \cdot 2 \%(-59 \cdot 3$ to $9 \cdot 3)$ & 0 & 0.199 & $-28 \cdot 2 \%(-74 \cdot 7$ to $6 \cdot 0)$ & $? ?$ & Ifakara $^{8}$ \\
\hline $\begin{array}{l}\text { Anaemia (reduced risk } \\
\text { of first or only episode) }\end{array}$ & 531 & 3839 & 0.14 & 522 & 3821 & 0.14 & $2.1 \%(-8.0$ to 11.2$)$ & 0 & 0.673 & $0.9 \%(-9 \cdot 5$ to $10 \cdot 2)$ & $? ?$ & Ifakara $^{8}$ \\
\hline 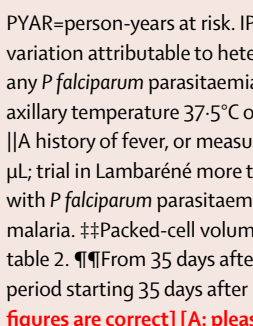 & $\begin{array}{l}\text { PT =interm } \\
\text { terogeneity } \\
\text { ia. History } \\
\text { or more fo } \\
\text { ured fever, } \\
\text { than } 600 \\
\text { nia more tl } \\
\text { ne less tha } \\
\text { er dose at } \\
\text { r last dose. }\end{array}$ & $\begin{array}{l}\text { of fever in } \\
\text { the trials } \\
\text { with a min } \\
\text { arasites p } \\
\text { an } 20000 \\
25 \% \text { in tr } \\
\text { months } \\
\text { [A: please } \\
\text { values ad }\end{array}$ & $\begin{array}{l}\text { ventive treatn } \\
\text { ted as I2. SThe } \\
\text { cluded report } \\
\text { in Ifakara, Na } \\
\text { imum P falci, } \\
\text { er } \mu L \text {; trial in } \\
\text { parasites pe } \\
\text { rials in Ifakara } \\
\text { or } 4 \text { months } 0 \\
\text { check all foc } \\
\text { ided and pro }\end{array}$ & $\begin{array}{l}\text { arum para } \\
\text { amale mor } \\
\mu L \text {. † Adm } \\
\text { Navrongo } \\
\text { fage until } \\
\text { tnotes are } \\
\text { vide the } m\end{array}$ & $\begin{array}{l}\text { ste densi } \\
\text { ethan } 50 \\
\text { issions to } \\
\text {, and Man } \\
\text { dose at } 9 \\
\text { cited cor } \\
\text { issing val }\end{array}$ & $\begin{array}{l}\text { emia, where t } \\
\text { moves the trii } \\
\text { st } 24 \mathrm{~h} \text { in the } \\
\text { lanhiça; recta } \\
\text { for each site } \\
\text { o parasites pe } \\
\text { paediatric W. } \\
\text { iça and a hae } \\
\text { lonths of age. } \\
\text { ctly] [A: inci } \\
\text { es] }\end{array}$ & $\begin{array}{l}\text { total number of children a } \\
\text { vith the highest protective } \\
\text { als in Ifakara and Manhiça, } \\
\text { tympanic temperature } 38 \\
\text { ssen to have a specificity o } \\
\text { IL; trial in Navrongo more } \\
\text { I with any P falciparum par } \\
\text { globin concentration less } \\
\text { IFrom } 35 \text { days after the do } \\
\text { nce has been added, so th }\end{array}$ & $\begin{array}{l}\text { an } 800 \\
\text { itaemi } \\
\text { an } 80 \\
\text { at } 9 \mathrm{~m} \\
\text { treade }\end{array}$ & $\begin{array}{l}\text { ted. } † \text { Prote } \\
\text { table 3. IPr } \\
\text { e past } 48 \mathrm{~h} \\
\text { it the trial in } \\
0 \% \text {; trials in } \\
\text { rasites per } \mu \\
\text { spective of } \\
\text { trials in Ku } \\
\text { is of age up } \\
\text { in compare }\end{array}$ & $\begin{array}{l}\text { ve efficacy defined as (1-F } \\
\text { lary definition: history of } \\
\text { the other four trials. Mea } \\
\text { thasi, and } 38.5^{\circ} \mathrm{C} \text { or more } \\
\text { kara, Manhiça, and Kuma } \\
\text { kE Episodes with a history } \\
\text { aptoms suggestive of mal } \\
\text { isi, Lambaréné, and Tama } \\
\text { the next dose of IPT or ag } \\
\text { T and placebo more easil }\end{array}$ & $\begin{array}{l}\text { R) } \times 100 \text {. } ¥ \mathrm{Pr} \\
\text { ever or mea } \\
\text { ured fever } \\
\text { for the trial } \\
\text { i more than } \\
\text { f fever or } m \\
\text { ria or a clini } \\
\text { SSFor defi } \\
15 \text { months } \\
\text { Please che }\end{array}$ & $\begin{array}{l}\text { portion of the } \\
\text { ured fever with } \\
\text { las defined as an } \\
n \text { Lambaréné. } \\
500 \text { parasites per } \\
\text { easured fever } \\
\text { :al diagnosis of } \\
\text { itions see } \\
* * * 5 \text {-month } \\
\text { ck that these }\end{array}$ \\
\hline
\end{tabular}

mortality in populations with poor access to curative 50 safety and efficacy outcomes to the analysis at 12 months health services. Although IPT did not affect mortality rates, it was associated with a reduced incidence of illness sufficiently severe to warrant hospital admission, reflecting a potential of IPT to save lives. A pooled analysis of safety and efficacy at 3 months after the last dose given (ie, including doses given between 12 months and 24 months) in four of the six trials showed similar

of age.

Careful assessment of safety is important when preventive interventions are being evaluated, since those given to healthy individuals need to have very high benefit-to-harm ratios. None of the serious dermatological adverse events in the IPT group was associated with study treatment. However, there was one suspected case
For more on the pooled analysis at 3 months after the last dose given see http://www.iptimalaria.org 


\begin{tabular}{|c|c|c|c|c|}
\hline & \multicolumn{2}{|l|}{ IPT } & \multicolumn{2}{|l|}{ Placebo } \\
\hline & Events & $\begin{array}{l}\text { Number of events } \\
\text { possibly related to } \\
\text { treatment }\end{array}$ & Events & $\begin{array}{l}\text { Number of events } \\
\text { possibly related to } \\
\text { treatment }\end{array}$ \\
\hline \multicolumn{5}{|c|}{ Deaths (number of deaths/number of infants [\%]) [A1] } \\
\hline Ifakara $^{8}$ & $5 / 350(0.9 \%)$ & 0 & $10 / 351(2 \cdot 8 \%)$ & 0 \\
\hline Navrong ${ }^{9 *}$ & $22 / 1221(1.8 \%)$ & 0 & $11 / 1225(0.9 \%)$ & 0 \\
\hline Manhiçą $^{10}$ & $20 / 748(2 \cdot 7 \%)$ & 0 & $22 / 755(2 \cdot 9 \%)$ & 0 \\
\hline Kumasi $^{11}$ & $3 / 535(0.6 \%)$ & 1 & $3 / 535(0.6 \%)$ & 0 \\
\hline Tamale $^{12}$ & $6 / 600(1.0 \%)$ & 0 & 7/599 (1.2\%) & 0 \\
\hline Lambaréné $e^{13}$ & $0 / 504(0 \%)$ & 0 & $0 / 507(0 \%)$ & 0 \\
\hline Total & $56 / 3958(1 \cdot 4 \%)$ & 1 & $53 / 3972(1 \cdot 3 \%)$ & 0 \\
\hline \multicolumn{5}{|c|}{ Non-fatal hospital admissions (number of admissions/PYAR [incidence per PYAR]) } \\
\hline Ifakara $^{8}$ & $106 / 248(0 \cdot 43)$ & 0 & $151 / 251(0.60)$ & 0 \\
\hline Navrongo $0^{9 *}$ & $248 / 874(0.28)$ & 0 & $309 / 867(0.26)$ & 0 \\
\hline Manhiça $\mathrm{a}^{10}$ & $227 / 495(0 \cdot 46)$ & 0 & $279 / 487(0.57)$ & 0 \\
\hline Kumasi $^{11} \dagger$ & $46 / 386(0.12)$ & 1 & $52 / 389[\mathrm{A3}](0.13)$ & 2 \\
\hline Tamale $^{12}$ & $23 / 402(0.06)$ & 1 & $52 / 401(0.13)$ & 1 \\
\hline Lambaréné ${ }^{13}$ & $26 / 327(0.08)$ & 2 & $17 / 330(0.05)$ & 2 \\
\hline Total [A2] & 676 & 4 & 860 & 5 \\
\hline \multicolumn{5}{|c|}{ Serious dermatological adverse events (number of events/PYAR [incidence per PYAR]) } \\
\hline Ifakara $^{8}$ & $0 / 248$ & 0 & $0 / 251$ & 0 \\
\hline Navrong ${ }^{9 *}$ & .. & & .. & \\
\hline Manhiça $a^{10}$ & $2 / 495(0.004)$ & 0 & $7 / 487(0.01)$ & 0 \\
\hline Kumasi $^{11}$ & $0 / 386$ & 0 & 2/398[A3](0.005) & 1 \\
\hline Tamale $^{12}$ & $0 / 402$ & 0 & $2 / 401(0.005)$ & 0 \\
\hline Lambaréné $e^{13}$ & $1 / 327(0.003)$ & 0 & $2 / 330(0.006)$ & 0 \\
\hline Total [A2] & 3 & 0 & 13 & 1 \\
\hline
\end{tabular}

IPT=intermittent preventive treatment. PYAR=person-years at risk. ."=data not available. *In the trial in Navrongo, no deaths or serious dermatological adverse events were judged related to treatment, but no more details are available. †In the trial in Kumasi, three hospital admissions in the sulfadoxine-pyrimethamine group and two in the placebo group were not assessable to work out causality. [A1: percentages and incidences have been added, so that readers can compare IPT and placebo more easily. Please check that these figures are correct] [A2: why is the denominator not present?] [A3: person-years at risk differ in this trial ( 389 for hospital admissions, 398 for SAEs), which is correct?]

Table 5: Deaths, non-fatal hospital admissions, and serious dermatological adverse events up to 12 months of age, or 3 months after the last dose of study treatment received, whichever is earlie
1 were highly unlikely to be Stevens-Johnson syndrome, ${ }^{30}$ because the syndrome is a severe disorder that requires intensive care, is associated with a high case-fatality rate, and a patient with the syndrome who is not admitted to 5 hospital in a rural African setting is unlikely to recover.

Large-scale implementation studies of IPT with sulfadoxine-pyrimethamine in infants are being done by the IPTi Consortium in Tanzania and by UNICEF in six other African countries [A: are there references for 10 these?]. Across these studies, more than 250000 infants a year are receiving three doses of IPT alongside routine vaccination delivered by the EPI. So far, no serious adverse events related to IPT have been reported to the consortium safety panel (Schellenberg D, unpublished 5 data; de Sousa A, [A: affiliation?], personal communication). Data obtained in the trials in Manhiça and Navrongo suggest that IPT with sulfadoxinepyrimethamine has no adverse effect on serological responses to vaccines for polio, hepatitis $\mathrm{B}$, measles, or 20 diphtheria, tetanus, and pertussis (DTP), ${ }^{9,10}$ and there are reassuring data on yellow fever vaccination [A: what do you mean here-there is less convincing evidence for yellow fever vaccines, or that the evidence is from the following report? Please rephrase to clarify] (Interim 25 report on IPTi with SP, WHO Advisory Committee on serological responses to EPI vaccines in infants receiving IPTi, WHO Internal Report 2006 [A: is this report in the public domain? If so, we would prefer to add to the reference list]).

30 The individual trials reported different findings for various extended follow-up periods after the last dose of IPT or placebo. Sustained protection against clinical malaria was seen up to the age of 2 years in children assigned to IPT in the trial in Ifakara. ${ }^{31}$ In children aged 35 between 16 months and 24 months in Navrongo, incidence of clinical malaria with a parasite density more than 5000 per $\mu \mathrm{L}$ was higher in the IPT group than in the placebo group. In the trial in Kumasi, the number of episodes of anaemia (haemoglobin $<75 \mathrm{~g} / \mathrm{L}$ ) during the of Stevens-Johnson syndrome in the placebo group of 40 8-month period starting 5 weeks after the last dose at the trial in Kumasi. Two further possible cases of this syndrome have also been reported in children from the same site, after they received a third dose of IPT [A: please confirm they were in the IPT group and not the placebo group] at 15 months of age. ${ }^{11}$ Both children recovered without admission to hospital and presented to the study team in the convalescent phase. The study team erred on the side of caution and reported suspected StevensJohnson syndrome, although the diagnosis has not been confirmed (May J, personal communication). After a 50 review of the existing information, reports, and a photograph of one of the cases, the consortium safety panel judged these two cases as unlikely to be Stevens-Johnson syndrome. IPT data, including the pooled analyses for safety and efficacy, were reviewed by a panel of experts convened by the US Institute of Medicine. The experts also concluded that these cases
15 months of age was higher in the ITP group than in the placebo group; however, this difference was not seen with definitions of anaemia of haemoglobin $70 \mathrm{~g} / \mathrm{L}$ or $80 \mathrm{~g} / \mathrm{L}$. In the trial in Tamale, the risk of severe malarial anaemia (haemoglobin $<50 \mathrm{~g} / \mathrm{L}$ ) during the 8-month period starting 1 month after the last IPT dose at 15 months of age in children assigned to IPT was about double the risk in children assigned to placebo. There was no evidence of either sustained protection or of increased risk during extended follow-up in the trials in Lambaréné and Manhiça. [A: this section is a little difficult to read and understand. Can you rephrase or present the results in a different way?]

Even though findings have not been consistent across different endpoints within or between trials, they have raised concerns that IPT in infants might impair the development of naturally acquired immunity to malaria. 
In the 5-month period starting 35 days after the last dose (ie, after treatment completion), [A: correct?] the incidence of hospital admissions associated with malaria parasitaemia was higher in the IPT group than in the placebo group; however, the pooled effect estimate did not reach statistical significance and there were no significant increases in incidence of clinical malaria or all-cause hospital admissions, or in risk of anaemia during this period. These findings contrast with the protective effect seen against these endpoints during the 1 intervention period and, thus, the balance of risks and benefits seem to favour IPT. Nevertheless, monitoring of morbidity should be part of studies of effectiveness and phase IV studies in which IPT in infants is implemented. A pooled analysis for a possible rebound effect was done 1 for those trials with extended follow-up periods (Ifakara, Manhiça, Lambaréné, and Navrongo); outcomes did not differ between IPT and placebo groups in the 11-month period starting 35 days after the last dose (data not shown).

The first trial of IPT in infants, undertaken in Ifakara, showed high protective efficacy of the intervention. Because of these results, additional trials were done; however, they reported lower estimates of protective efficacy. Protective efficacy against clinical malaria was 25 similar between trials during all periods analysed, apart from during the inter-dose period, when efficacy was higher in the trial in Ifakara than in the other trials. Because of the differences in trial design between the six studies, we were unable to draw conclusions about the 30 conditions under which IPT in infants might have the best possible effect. However, a detailed comparison between very similar trials in Ifakara and Manhiça ${ }^{32}$ suggested that the combined use of insecticide-treated bednets and IPT might explain the higher efficacy reported in the Ifakara trial. Nevertheless, when sulfadoxine-pyrimethamine and artesunate were coadministered as IPT in a trial in western Kenya, where use of insecticide-treated bednets was very high, efficacy [A: against clinical malaria?] was less than 30\% (Newman R, Slutsker L, unpublished data).

Parasite resistance to sulfadoxine-pyrimethamine has spread across Africa, which could undermine the efficacy of IPT in infants. The highest reported frequency of resistance during the trials was 31\% (as measured by the 45 WHO standard day 14 in-vivo clinical and parasitological resistance in 6-59-month-old symptomatic children). This level of resistance, which corresponds with intermediate levels as defined by ter Kuile and colleagues, ${ }^{33}$ did not preclude protective efficacy when sulfadoxine-pyrimethamine was used for IPT in infants. Furthermore, the site with the highest level of resistance to the drug combination (Ifakara) ${ }^{34}$ had the highest efficacy of IPT, and in all trials (apart from in Lambaréné and after the last dose of IPT in Kumasi), there was 5 significant protection in the month after an IPT dose. These findings call into question the value of estimates

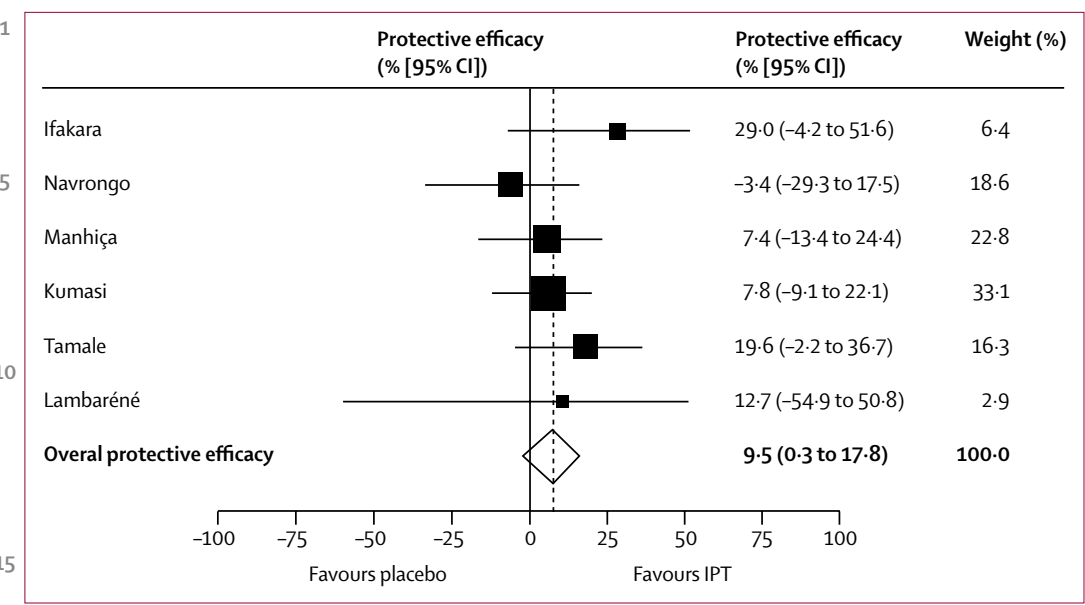

Figure 3: Combined estimates for the protective efficacy of IPT with sulfadoxine-pyrimethamine in infants against clinical malaria from 35 days after the dose at 9 months of age until next dose or 15 months of age The width of the diamond represents the $95 \% \mathrm{Cl}$ interval in the overall pooled protective efficacy estimate. [A: vertical line moved to $0 \%$. Ok?]

of curative efficacy to inform the use of antimalarial drugs for prevention where infections might be of low density and asymptomatic [A: meaning of highlighted sentence unclear; please rephrase]. Moreover, the increasing use of artemisinin-based combination therapy will lead to a reduction in the use of sulfadoxinepyrimethamine, reducing the spread of resistance and prolonging the duration for which this drug combination could be useful for IPT. A corresponding concern is that IPT with sulfadoxine-pyrimethamine in infants might facilitate the spread of drug resistance. Although the prevalence of markers of resistance to sulfadoxinepyrimethamine increases after doses in infants, ${ }^{35,36}$ mathematical models suggest that the size of such effect in the global spread of resistance will be small. ${ }^{37}$ At present, sulfadoxine-pyrimethamine is the only antimalarial drug available for IPT in both pregnancy and infancy, in view of the combination's long half-life and prophylactic effect, established safety profile, acceptability, ${ }^{7,38}$ and affordability. IPT seems to work by prophylaxis, with sulfadoxine-pyrimethamine providing protection for up to 6 weeks in infants. ${ }^{39,40}$ New longacting antimalarial drugs are urgently needed for use in IPT in infants.

Where malaria transmission is highly seasonal and severe malaria occurs rarely in infants, methods for delivering IPT to older children might be needed. ${ }^{41}$ However, in areas with a substantial burden of malaria in infants, delivery of IPT through WHO's EPI system has been shown to be highly cost effective. ${ }^{42}$

[A: please provide a brief paragraph discussing the limitations of your analysis]

This pooled analysis substantiates the notion that IPT is safe and efficacious in infants. Furthermore, operational experience from Tanzania ${ }^{43}$ and six other African countries [A: reference?] shows that rapid large-scale deployment of IPT is feasible. Thus, this intervention
For the pooled analysis of the extended follow-up period see http://www.ipti-malaria.org 
could make an important contribution to reducing the 112 Mockenhaupt FP, Reither K, Zanger P, et al. Intermittent intolerable burden of malaria in infants and should be integrated with other effective control methods. ${ }^{32,44-50}$

\section{Contributors}

JJA, IC, ID, RK, BL, JM, and SS developed and undertook the pooled efficacy analysis. AB, JC, AD, ZP, ES, RS-B, and PW compiled and analysed the safety information. SAd, PA, SAn, DC, BG, MPG, SI, PGK, EM, JM, CM, FM, HM, SO-A, DS, and TM were principal and coprincipal investigators of the six randomised controlled clinical trials and shared the data used for the analyses presented in this report. AE was the coordinator of the IPTi Consortium, coordinated the pooled analyses, and was involved in the development of this report. PA, BG, MPG, PGK, $\mathrm{CM}, \mathrm{RDN}, \mathrm{DS}, \mathrm{LS}$, and MT had a key role in the development and establishment of the IPTi Consortium, providing overall leadership in the activities and development of the analyses and this report. PA, JJA, $\mathrm{AB}, \mathrm{JC}, \mathrm{AE}, \mathrm{CM}$, and DS wrote the manuscript. All authors saw and approved the final version of the report [A: correct?].

\section{Conflicts of interest}

We declare that we have no conflicts of interest.

\section{Acknowledgments}

The Bill \& Melina Gates Foundation funded the pooled analyses through grants to the IPTi Consortium. We thank David Brandling-Bennett, the senior programme officer for the IPTi Consortium at the Bill \& Melina Gates Foundation; Jane Crawley, who was involved in the development and direction of the IPTi Consortium; Cornelia Bevilacqua, who monitored or audited the trials; Llorenç Quinto, who helped in the extraction of the safety data of the Manhiça trial; and Wibke Loag, who was involved in data management and extraction of data of the Kumasi trial.

\section{References}

1 Menendez C, Kahigwa E, Hirt R, et al. Randomised placebo-controlled trial of iron supplementation and malaria chemoprophylaxis for prevention of severe anaemia and malaria in Tanzanian infants. Lancet 1997; 350: 844-50.

2 Greenwood BM, David PH, Otoo-Forbes LN, et al. Mortality and morbidity from malaria after stopping malaria chemoprophylaxis. Trans R Soc Trop Med Hyg 1995; 89: 629-33.

3 Aponte JJ, Menendez C, Schellenberg D, et al. Age interactions in the development of naturally acquired immunity to Plasmodium falciparum and its clinical presentation. PLoS Med 2007; 4: e242.

4 Menon A, Snow RW, Byass P, Greenwood BM, Hayes RJ, N'Jie AB. Sustained protection against mortality and morbidity from malaria in rural Gambian children by chemoprophylaxis given by village health workers. Trans R Soc Trop Med Hyg 1990; 84: 768-72.

5 Otoo LN, Riley EM, Menon A, Byass P, Greenwood BM. Cellular immune responses to Plasmodium falciparum antigens in children receiving long term anti-malarial chemoprophylaxis. Trans R Soc Trop Med Hyg 1989; 83: 778-82.

6 WHO Expert Committee on Malaria. Twentieth report. 892nd edn. Geneva: World Health Organization, 2000. [A: is there a URL for this report?]

7 WHO. A strategic framework for malaria prevention and control during pregnancy in the African region. Report AFR/MAL/04/01 Brazzaville, Democratic Republic of Congo: WHO Regional Office for Africa, 2004.

8 Schellenberg D, Menendez C, Kahigwa E, et al. Intermittent treatment for malaria and anaemia control at time of routine vaccinations in Tanzanian infants: a randomised, placebo-controlled trial. Lancet 2001; 357: 1471-77.

9 Chandramohan D, Owusu-Agyei S, Carneiro I, et al. Cluster randomised trial of intermittent preventive treatment for malaria in infants in area of high, seasonal transmission in Ghana. BMJ 2005; 331: 727-33.

10 Macete E, Aide P, Aponte JJ, et al. Intermittent preventive treatment for malaria control administered at the time of routine vaccinations in Mozambican infants: a randomized, placebo-controlled trial. $J$ Infect Dis 2006; 194: 276-85.

11 Kobbe R, Kreuzberg C, Adjei S, et al. A randomized controlled trial 55 of extended intermittent preventive antimalarial treatment in infants. Clin Infect Dis 2007; 45: 16-25. preventive treatment in infants as a means of malaria control: a randomized, double-blind, placebo-controlled trial in northern Ghana. Antimicrob Agents Chemother 2007; 51: 3273-81.

13 Grobusch MP, Lell B, Schwarz NG, et al. Intermittent preventive treatment against malaria in infants in Gabon-a randomized, double-blind, placebo-controlled trial. J Infect Dis 2007; 196: $1595-602$.

14 Egan A, Crawley J, Schellenberg D, IPTi Consortium. Intermittent preventive treatment for malaria control in infants: moving towards evidence-based policy and public health action. Trop Med Int Health 2005; 10: 815-17.

15 Schellenberg D, Cisse B, Menendez C. The IPTi Consortium: research for policy and action. Trends Parasitol 2006; 22: 296-300.

16 Grobusch MP, Egan A, Gosling RD, Newman RD. Intermittent preventive therapy for malaria: progress and future directions. Curr Opin Infect Dis 2007; 20: 613-20.

17 Planche T, Krishna S, Kombila M, et al. Comparison of methods for the rapid laboratory assessment of children with malaria. Am J Trop Med Hyg 2001; 65: 599-602.

18 Roche Laboratories Inc. Fansidar (Sufadoxine and pyrimethamine). Product Information, 2009.

19 Smith T, Armstrong J, Hayes R. Attributable fraction estimates and case definitions for malaria in endemic areas. Stat Med 1994; 13: 2345-58

2020 Zou G. A modified poisson regression approach to prospective studies with binary data. Am J Epidemiol 2004; 159: 702-06.

21 WHO/Uppsala Monitoring Centre. Safety monitoring of medicinal products. Guidelines for setting up and running a pharmacovigilance Centre. Upssala: Upssala Monitoring Centre, 2000.

2522 Higgins JP, Thompson SG, Deeks JJ, Altman DG. Measuring inconsistency in meta-analyses. BMJ 2003; 327: 557-60.

23 Massaga JJ, Kitua AY, Lemnge MM, et al. Effect of intermitten treatment with amodiaquine on anaemia and malarial fevers in infants in Tanzania: a randomised placebo-controlled trial. Lancet 2003; 361: 1853-60.

24 Desai MR, Mei JV, Kariuki SK, et al. Randomized, controlled trial of daily iron supplementation and intermittent sulfadoxinepyrimethamine for the treatment of mild childhood anemia in western Kenya. I Infect Dis 2003; 187: 658-66.

25 Verhoef $\mathrm{H}$, West CE, Nzyuko SM, et al. Intermittent administration of iron and sulfadoxine-pyrimethamine to control anaemia in Kenyan children: a randomised controlled trial. Lancet 2002; 360: 908-14.

26 Clarke SE, Jukes MC, Njagi JK, et al. Effect of intermittent preventive treatment of malaria on health and education in schoolchildren: a cluster-randomised, double-blind, placebo-controlled trial. Lancet 2008; 372: 127-38.

27 Cisse B, Sokhna C, Boulanger D, et al. Seasonal intermitten preventive treatment with artesunate and sulfadoxine-pyrimethamine for prevention of malaria in Senegalese children: a randomised, placebo-controlled, double-blind trial. Lancet 2006; 367: 659-67.

28 Sokhna C, Cisse B, Ba el H, et al. A trial of the efficacy, safety and impact on drug resistance of four drug regimens for seasona intermittent preventive treatment for malaria in Senegalese children. PLoS One 2008; 3: e1471.

45 Dicko A, Sagara I, Sissoko MS, et al. Impact of intermittent preventive treatment with sulphadoxine-pyrimethamine targeting the transmission season on the incidence of clinical malaria in children in Mali. Malar J 2008; 7: 123.

30 Institute of Medicine. Assessment of the role of intermittent preventive treatment for malaria in infants: letter report. Washington, DC, USA: The National Academies Press, 2008.

31 Schellenberg D, Menendez C, Aponte JJ, et al. Intermittent preventive antimalarial treatment for Tanzanian infants: follow-up to age 2 years of a randomised, placebo-controlled trial. Lancet 2005 ; 365: 1481-83.

32 Menendez C, Schellenberg D, Macete E, et al. Varying efficacy of intermittent preventive treatment for malaria in infants in two similar trials: public health implications. Malar J 2007; 6: 132 . 
33 ter Kuile FO, van Eijk AM, Filler SJ. Effect of sulfadoxinepyrimethamine resistance on the efficacy of intermittent preventive therapy for malaria control during pregnancy: a systematic review. JAMA 2007; 297: 2603-16.

34 Schellenberg D, Kahigwa E, Drakeley C, et al. The safety and efficacy of sulfadoxine-pyrimethamine, amodiaquine, and their combination in the treatment of uncomplicated Plasmodium falciparum malaria. Am J Trop Med Hyg 2002; 67: 17-23.

35 Mayor A, Serra-Casas E, Sanz S, et al. Molecular markers of resistance to sulfadoxine-pyrimethamine during intermittent preventive treatment for malaria in Mozambican Infants. J Infect Dis 2008; 197: 1737-42.

36 Marks F, von Kalckreuth V, Kobbe R, et al. Parasitological rebound effect and emergence of pyrimethamine resistance in Plasmodium falciparum after single-dose sulfadoxine-pyrimethamine. J Infect Dis 2005; 192: 1962-65.

37 Alexander N, Sutherland C, Roper C, Cisse B, Schellenberg D. Modelling the impact of intermittent preventive treatment for malaria on selection pressure for drug resistance. Malar J 2007; 6: 9.

38 Pool R, Munguambe K, Macete E, et al. Community response to intermittent preventive treatment delivered to infants (IPTi) through the EPI system in Manhica, Mozambique. Trop Med Int Health 2006; 11: 1670-78.

39 May J, Adjei S, Busch W, et al. Therapeutic and prophylactic effect of intermittent preventive anti-malarial treatment in infants (IPTi) from Ghana and Gabon. Malar J 2008; 7: 198.

40 Cairns M, Carneiro I, Milligan P, et al. Duration of protection against malaria and anaemia provided by intermittent preventive treatment in infants in Navrongo, Ghana. PLoS One 2008; 3: e2227.
141 Chandramohan D, Webster J, Smith L, Awine T, Owusu-Agyei S, Carneiro I. Is the Expanded Programme on Immunisation the most appropriate delivery system for intermittent preventive treatment of malaria in West Africa? Trop Med Int Health 2007; 12: 743-50.

42 Hutton G, Schellenberg D, Tediosi F, Macete E, Kahigwa E,

5 Sigauque B. Cost effectiveness of malaria intermittent preventive treatment in infants (IPTi) in Mozambique and the United Republic of Tanzania. Bull World Healt Organ 2009; 87: 123-29.

43 Manzi F, Schellenberg J, Hamis Y, et al. Intermittent preventive treatment for malaria and anaemia control in Tanzanian infants; the development and implementation of a public health strategy. Trans R Soc Trop Med Hyg 2009; 103: 79-86.

1044 Munday S. Review of intermittent preventive treatment for malaria in infants and children. J Paediatr Child Health 2007; 43: 424-28.

45 Schellenberg D, Abdulla S, Roper C. Current issues for anti-malarial drugs to control P falciparum malaria. Curr Mol Med 2006; 6: 253-60.

46 Ter Kuile FO, Steketee RW. Intermittent preventive treatment in infants-adjusting expectations and seeing opportunity. J Infect Dis 2006; 194: 269-72.

15 Breman JG, O’Meara WP. Intermittent preventive treatment for malaria in infants: moving forward, cautiously. J Infect Dis 2005 192: 1869-71.

48 O'Meara WP, Breman JG, McKenzie FE. The promise and potentia challenges of intermittent preventive treatment for malaria in infants (IPTi). Malar J 2005; 4: 33.

2049 Kruger C. Malaria intermittent preventive treatment and EPI coverage. Lancet 2004; 363: 2000-01.

50 Rosen JB, Breman JG. Malaria intermittent preventive treatment in infants, chemoprophylaxis, and childhood vaccinations. Lancet 2004; 363: 1386-88 